\title{
The role of fluconazole in the regulation of fatty acid and unsaponifiable matter biosynthesis in Schizochytrium sp. MYA 1381
}

Jun Li ${ }^{1}$, Hao Zhou' ${ }^{1}$ Xueshan Pan ${ }^{1}$, Zhipeng $\mathrm{Li}^{1}$, Yinghua Lu', ${ }^{1,2}$, Ning He $\mathrm{H}^{1,3}$, Tong Meng ${ }^{1}$, Chuanyi Yao ${ }^{1,3}$, Cuixue Chen ${ }^{1}$ and Xueping Ling ${ }^{1,3^{*}}$ (D)

\begin{abstract}
Background: Schizochytrium has been widely used in industry for synthesizing polyunsaturated fatty acids (PUFAs), especially docosahexaenoic acid (DHA). However, unclear biosynthesis pathway of PUFAs inhibits further production of the Schizochytrium. Unsaponifiable matter (UM) from mevalonate pathway is crucial to cell growth and intracellular metabolism in all higher eukaryotes and microalgae. Therefore, regulation of UM biosynthesis in Schizochytrium may have important effects on fatty acids synthesis. Moreover, it is well known that UMs, such as squalene and $\beta$-carotene, are of great commercial value. Thus, regulating UM biosynthesis may also allow for an increased valuation of Schizochytrium.

Results: To investigate the correlation of UM biosynthesis with fatty acids accumulation in Schizochytrium, fluconazole was used to block the sterols pathway. The addition of $60 \mathrm{mg} / \mathrm{L}$ fluconazole at $48 \mathrm{~h}$ increased the total lipids (TLs) at $96 \mathrm{~h}$ by $16 \%$ without affecting cell growth, which was accompanied by remarkable changes in UMs and NADPH. Cholesterol content was reduced by $8 \%$, and the squalene content improved by $45 \%$ at $72 \mathrm{~h}$, which demonstrated fluconazole's role in inhibiting squalene flow to cholesterol. As another typical UM with antioxidant capacity, the $\beta$-carotene production was increased by $53 \%$ at $96 \mathrm{~h}$. The increase of squalene and $\beta$-carotene could boost intracellular oxidation resistance to protect fatty acids from oxidation. The NADPH was found to be 33\% higher than that of the control at $96 \mathrm{~h}$, which meant that the cells had more reducing power for fatty acid synthesis. Metabolic analysis further confirmed that regulation of sterols was closely related to glucose absorption, pigment biosynthesis and fatty acid production in Schizochytrium.
\end{abstract}

Conclusion: This work first reported the effect of UM biosynthesis on fatty acid accumulation in Schizochytrium. The UM was found to affect fatty acid biosynthesis by changing cell membrane function, intracellular antioxidation and reducing power. We believe that this work provides valuable insights in improving PUFA and other valuable matters in microalgae.

Keywords: Schizochytrium, Fluconazole, Unsaponifiable matter, Metabolic analysis, Fatty acids.

\footnotetext{
* Correspondence: xpling@xmu.edu.cn

${ }^{1}$ Department of Chemical and Biochemical Engineering, College of Chemistry

and Chemical Engineering, Xiamen University, Xiamen 361005, People's

Republic of China

${ }^{3}$ The Key Lab for Synthetic Biotechnology of Xiamen City, Xiamen University,

Xiamen 361005, People's Republic of China

Full list of author information is available at the end of the article
}

(c) The Author(s). 2019 Open Access This article is distributed under the terms of the Creative Commons Attribution 4.0 International License (http://creativecommons.org/licenses/by/4.0/), which permits unrestricted use, distribution, and reproduction in any medium, provided you give appropriate credit to the original author(s) and the source, provide a link to the Creative Commons license, and indicate if changes were made. The Creative Commons Public Domain Dedication waiver (http://creativecommons.org/publicdomain/zero/1.0/) applies to the data made available in this article, unless otherwise stated. 


\section{Background}

Schizochytrium sp., a kind of marine microalga, has drawn increasing attention for synthesizing significant amounts of total lipids rich in PUFAs, especially docosahexaenoic acid (DHA,22:6) [1]. DHA is an $\omega-3$ PUFA and plays an important role in promoting mental development in infants and preventing cardiovascular diseases [2]. Novel sources of $\omega-3$ PUFA can be green manufactured from Schizochytrium sp., which could also eliminate many problems such as bad taste from the traditional source of fish oil [3]. Schizochytrium sp. was reported to synthesize PUFAs through polyketide synthase (PKS) and fatty acid synthase (FAS) pathways [4]. In recent years, most studies attempted to elucidate the PUFA synthesis pathway based on regulation of key genes related to biosynthesis in order to improve PUFA production [5-8]. However, in these studies, genetic engineering methods such as use of genetically engineered microorganisms are employed. It should be noted that, the genetically engineered microorganisms have been widely questioned in the food field [9]. More importantly, most studies were hindered due to the unknown mechanism of PUFA synthesis in Schizochytrium sp. In addition, PUFA synthesis is also affected by other related metabolic pathways because of the complexity of metabolism. Therefore, regulating other related metabolic pathways may be an effective method to increase PUFAs production [10].

Ren et al. found that the content of PUFAs has a positive correlation with UM concentration [11]. Compared to fatty acids, UM refers to lipid-soluble matter that could not undergo saponification including pigments, squalene and sterols, which are isoprenoid compounds synthesized by the mevalonate acid (MVA) pathway (Fig. 1). As a pathway of UM synthesis, the MVA plays an important role in cell growth and intracellular metabolism and exists in all higher eukaryotes and many viruses [12]. In the initial step, two molecules of acetyl-CoA (which is also the initial substrate of fatty acid synthesis) undergo condensation to yield acetoacetyl-CoA, which is subsequently converted to 3-hydroxy-3-methylglutaryl-CoA (HMG-CoA) by the gene product of 3-Hydroxy-3-methylglutaryl-coenzyme A synthase $(h m g s)$. HMG-CoA is further converted

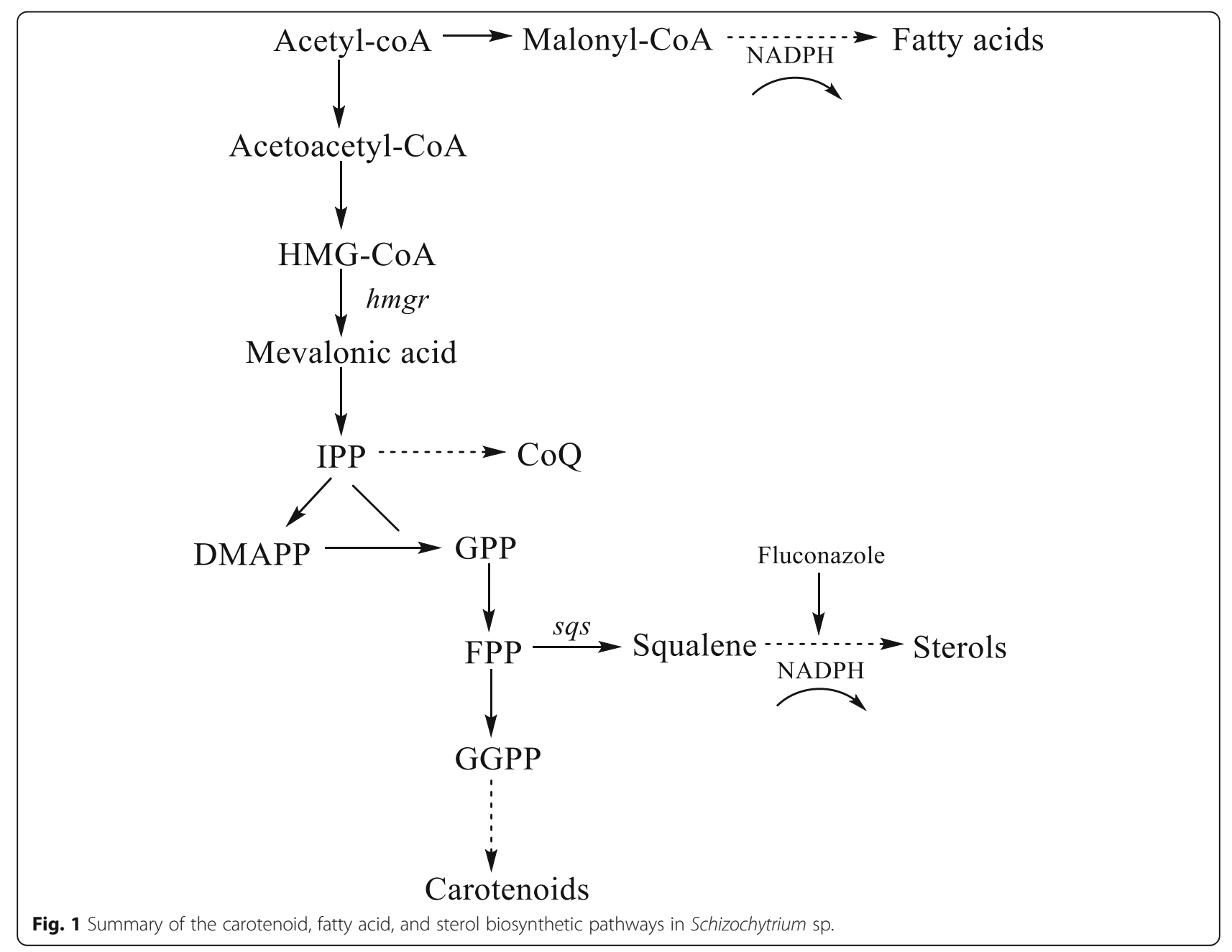


to MVA by the gene product of hmgr, which is the ratelimiting step of the MVA pathway [13]. Then, MVA is further converted to isopentenyl diphosphate (IPP), which is the precursor of coenzyme $\mathrm{Q}(\mathrm{CoQ})$ a hydrogen carrier in the electron transport chain and the necessary ingredients for mitochondrial ATP synthesis [14]. Farnesyl diphosphate (FPP) is synthesized from IPP in several steps [15]. FPP is a crucial molecule in the MVA pathway. Specifically, it is condensed directly by squalene synthase (sqs) to squalene, which is subsequently converted to sterols [16]. The other FPP is condensed to carotenoids through a series of condensation, dehydrogenation and cyclization reactions.

The UM from MVA pathway is important to intracellular metabolism. It is well known that both sterols and fatty acids are the main components of the cell membrane, which has a significant influence on fatty acid synthesis [17]. Bernsdorff et al. found out that different sterols have different effects on the regulation of the cell membrane due to their distinctive molecular structures [18]. Squalene is a natural antioxidant that is capable of removing excess free radicals in cells, thus protecting lipids from peroxidation $[19,20]$. On the other hand, carotenes have a close relationship with intracellular oxidative stress, which has a significant relationship with cell growth and lipid accumulation [21, 22]. Rice et al. reported that the gene $m g a 2$, which encodes an important regulator of unsaturated fatty acid production in Saccharomyces cerevisiae, affected transcription and expression of the $\operatorname{erg} 1$ gene, which encodes squalene oxidase. The $m g a 2$ deletion strain had relatively elevated amounts of squalene compared to wild-type cells [23]. This UM is crucial to the cell growth and fatty acid biosynthesis. Therefore, regulation of UM biosynthesis in Schizochytrium sp. may have important effects on the synthesis of fatty acids. Moreover, it is well known that UM, such as squalene and $\beta$-carotene, may be of great commercial value. Thus, regulating UM biosynthesis may also allow for an increased valuation of Schizochytrium.

Fluconazole, a type of antifungal agent, blocks the sterol pathway by inhibiting lanosterol $14 \alpha$-demethylase activity [24]. At present, fluconazole is mainly used as a drug in the treatment of fungal infections. Miao et al. found that blocking the sterol pathway with $60 \mathrm{mg} / \mathrm{L}$ fluconazole could increase astaxanthin content to 5 -fold higher than that of the control in P. rhodozyma [25], which indicates that fluconazole could be used to regulate UM metabolism. Based on this result, fluconazole was added to the medium in this study to investigate its effects on UM and fatty acid biosynthesis in Schizochytrium sp. MYA 1381. Our work aims to illuminate the relationship between fatty acid and UM biosynthesis in providing a strategy for regulating the production of PUFAs in Schizochytrium and also explore additional value of the Schizochytrium.

\section{Materials and methods}

Medium, strains, and culture conditions

Schizochytrium sp. MYA1381 was obtained from the American Type Culture Collection (USA) and maintained on seed broth agar plates. The fermentation and seed broths were the same as those used in our previous study [26]. After three generations of cultivation, the seed culture $(4 \% \mathrm{v} / \mathrm{v})$ was then transferred to a $250 \mathrm{~mL}$ flask containing $100 \mathrm{~mL}$ fermentation broth and was incubated at $28^{\circ} \mathrm{C}$ and $200 \mathrm{rpm}$ for $120 \mathrm{~h}$ or more in the dark. Fluconazole $(60 \mathrm{mg} / \mathrm{L})$ was dissolved in methanol and added to the fermentation broth. Each treatment was repeated three times. Samples from the control and fluconazole groups were collected every $24 \mathrm{~h}$ until the total fermentation time reached $120 \mathrm{~h}$. The biomass, lipid content, fatty acid and metabolic profile were analyzed as described below.

\section{Determination of dry cell weight (DCW) and glucose}

One milliliter of broth was transferred to a pre-weighed centrifuge tube and then centrifuged at $8000 \times \mathrm{g}$ for 2 min. The cell pellet was washed twice with distilled water and lyophilized to a constant weight at $-50{ }^{\circ} \mathrm{C}$ for approximately $24 \mathrm{~h}$. DCW was then weighed. The supernatant from the centrifugation was collected to measure the residual glucose concentration. The glucose concentration was determined by the 3,5-dinitrosalicylic acid (DNS) method [27].

\section{Lipid extraction and fatty acid composition analysis}

Three milliliters of fermentation broth was mixed with $4 \mathrm{~mL} \mathrm{HCl}(12 \mathrm{~N})$ and incubated in a water bath at $65^{\circ} \mathrm{C}$ for $45 \mathrm{~min}$. TLs from the mixture were extracted four times with $3 \mathrm{~mL}$ n-hexane, and then the lipid extract was purified and dried by evaporation. Total fatty acids (TFA) production was calculated by subtracting UM from TLs, where UM was isolated from lipids by saponification [28]. The fatty acid methyl esters (FAMEs) preparation and analysis were performed according to our previous study [26].

\section{Isolation and analysis of cholesterol, squalene and $\beta$ - carotene}

The UM isolated from lipids by saponification was prepared for measuring cholesterol and squalene. Cholesterol measurements were performed according to the GB/T 5009.128-2003. Squalene was analyzed by a GC system (Agilent GC 7890, USA) according to a previous study [29]. Because $\beta$-carotene is easily oxidized, it was extracted from cells to prevent saponification. Cells were harvested by centrifugation at $8000 \times \mathrm{g}$ and washed with deionized water and then suspended with $5 \mathrm{~mL}$ petroleum ether/acetone mixture $(7: 3, \mathrm{vol} / \mathrm{vol})$, followed by homogenate with a high- pressure homogenizer to 
release intracellular metabolites. After centrifugation, the supernatant was analyzed using high-performance liquid chromatography to measure the $\beta$-carotene content according to our previous study [30].

\section{Determination of G6PDH and NADPH}

The glucose-6-phosphate dehydrogenase (G6PDH) activities were determined according to a previous study with minor modifications [31]. Cells were harvested by centrifugation at $4000 \times \mathrm{g}$ for $2 \mathrm{~min}$. The pellet was suspended in PBS buffer and then broken by a high-pressure homogenizer. The disrupted cell suspension was centrifuged at $12000 \times \mathrm{g}$ for $10 \mathrm{~min}$ at $4{ }^{\circ} \mathrm{C}$, and the supernatant was used for G6PDH activities. G6PDH was determined using continuous spectrophotometric assays following the increase of NADPH at $340 \mathrm{~nm}$, and the enzyme activity was defined as the reducing amount of $\mathrm{NADP}^{+}$ (nmol) catalyzed by the enzyme solution with $1 \mathrm{mg}$ of protein in $1 \mathrm{~min}\left(\mathrm{nmol} \mathrm{min}{ }^{-1}(\mathrm{mg} \text { protein })^{-1}\right)$. The $\mathrm{NADPH}$ content was measured by an NADP/NADPH quantification kit (Sigma). The protein concentrations of enzyme solutions were determined according to the method of Bradford [32].

\section{Preparation of metabolome samples}

Cells from the control and fluconazole groups were collected every $24 \mathrm{~h}$ from $72 \mathrm{~h}$ to $120 \mathrm{~h}$. The metabolome samples of Schizochytrium were prepared according to the procedures of $\mathrm{Yu}$ et al. with minor modifications [33]. Five milliliters of the samples from different time points were quickly harvested and immediately mixed with $5 \mathrm{~mL}$ of prechilled pure methanol $\left(-40^{\circ} \mathrm{C}, \mathrm{v} / \mathrm{v}\right)$ to quench the culture. The quenched cells were washed twice with $5 \mathrm{~mL}$ cold physiological saline $(0.9 \%$ of sodium chloride solution) and ground into a fine powder with liquid nitrogen. For extraction, cell powder (approximately $0.15 \mathrm{~g}$ ) was transferred into a $1.5 \mathrm{~mL}$ Eppendorf tube and then extracted twice with $0.5 \mathrm{~mL}$ of prechilled methanol $\left(-40^{\circ} \mathrm{C}\right)$. $1 \mathrm{~mL}$ of sample obtained above and $5 \mu \mathrm{L}$ of internal standard (heptadecanoic acid in n-hexane, $16 \mathrm{mg} / \mathrm{mL}$ ) were mixed and dried in a vacuum centrifuge dryer. Sample derivatization procedures were performed according to the method of Yu et al. [34].
GC-MS analysis and data analysis of metabolomics The sample was analyzed by GC-MS using an Agilent 7890-5975C GC-MS solution system (Agilent, Sacramento, USA) with an hp-5 capillary column (30 $\mathrm{m} \times$ $0.25 \mathrm{~mm}, 0.25 \mu \mathrm{m}$ film thickness; Agilent J.W. Scientific, Folsom, USA). One microliter of sample was injected into the DB-5MS capillary column coated with 5\% phenyl and 95\% methylpoly siloxane in split-less mode. The column temperature was held at $70^{\circ} \mathrm{C}$ for $2 \mathrm{~min}$ and then increased to $290^{\circ} \mathrm{C}$ at a rate of $8^{\circ} \mathrm{C} / \mathrm{min}$ and held for $3 \mathrm{~min}$. Helium was used as a carrier gas, and the flow was constant at $1 \mathrm{~mL} / \mathrm{min}$. The transfer line and ion source temperatures were $280{ }^{\circ} \mathrm{C}$ and $250{ }^{\circ} \mathrm{C}$, respectively. The mass scan range was $50-600 \mathrm{~m} / \mathrm{z}$. A supervised partial least-squares discriminant analysis (PLS-DA) was subsequently performed to identify the metabolites contributing to differences between the control group and the fluconazole group. A metabolite with a variable influence on the projection value (VIP) higher than 1 indicates a significant contribution to the separation of groups in PL-SDA models.

\section{Results and discussion}

Effects of fluconazole on cell growth, fatty acid and DHA production in Schizochytrium

In this study, various fluconazole concentrations $(0,20$, 40,60 , and $80 \mathrm{mg} / \mathrm{L}$ ) were added at a culture time of 24 $\mathrm{h}$ to examine the effect of fluconazole on Schizochytrium. Compared with the control group $(0 \mathrm{mg} / \mathrm{L})$, the addition of fluconazole had little effect on cell growth. On the other hand, the fluconazole caused an increase in total lipids (TLs) and DHA yields at $96 \mathrm{~h}$. Specifically, TLs and DHA contents (\%DCW) increased to $24.5 \mathrm{~g} / \mathrm{L}$ and $5.6 \mathrm{~g} / \mathrm{L}$, respectively, when $60 \mathrm{mg} / \mathrm{L}$ fluconazole was added (Table 1). To explore the influence of fluconazole on Schizochytrium, $60 \mathrm{mg} / \mathrm{L}$ fluconazole was added to the medium at three cultivation stages (0,24 and $48 \mathrm{~h}$ ). As shown in Table 2, the DCW had no obvious difference in all groups, meanwhile the TLs had a specific increase in three fluconazole groups. After the addition of $60 \mathrm{mg} / \mathrm{L}$ fluconazole at $48 \mathrm{~h}$, the TLs increased to a maximum value of $25.3 \mathrm{~g} / \mathrm{L}$, which is $16 \%$ higher than that of control at $96 \mathrm{~h}$, and were consequently chosen for further experiments. To investigate the effects of

Table 1 Effects of different concentrations of fluconazole on dry cell weight (DCW), total lipids (TLs), DHA yield and DHA/TFA at 96 $\mathrm{h}$ in Schizochytrium. Values are presented as the mean \pm standard deviation $(n=3)$

\begin{tabular}{llllll}
\hline & \multicolumn{4}{l}{ Fluconazole concentration $(\mathrm{mg} / \mathrm{L})$} & \\
\cline { 2 - 5 } & 0 & 20 & 40 & 60 & 80 \\
\hline Dry Cell Weight (DCW) (g/L) & $43.6 \pm 0.1$ & $42.5 \pm 0.5$ & $41.8 \pm 0.3$ & $41.7 \pm 0.1$ & $43.3 \pm 0.6$ \\
Total Lipids (TLs) $(\mathrm{g} / \mathrm{L})$ & $21.1 \pm 0.6$ & $24.3 \pm 0.2$ & $23.4 \pm 1.2$ & $24.5 \pm 0.1$ & $22.4 \pm 1.1$ \\
DHA (g/L) & $5.0 \pm 0.3$ & $5.5 \pm 0.1$ & $5.4 \pm 0.4$ & $5.6 \pm 0.1$ & $5.2 \pm 0.4$ \\
DHA/TFA & $24 \pm 0.2$ & $23 \pm 0.2$ & $23 \pm 0.1$ & $23 \pm 0.1$ & $23 \pm 0.7$ \\
\hline
\end{tabular}


Table 2 Effects of $60 \mathrm{mg} / \mathrm{L}$ fluconazole added at different cultivation time on dry cell weight (DCW), total lipids (TLs), DHA and DHA/TFA in Schizochytrium. Values are presented as the mean \pm standard deviation $(n=3)$

\begin{tabular}{lllll}
\hline & Control & \multicolumn{3}{l}{ Addition time of fluconazole } \\
\cline { 3 - 5 } & & $0 \mathrm{~h}$ & $24 \mathrm{~h}$ & \\
\hline Dry Cell Weight (DCW) (g/L) & $43.8 \pm 1.1$ & $42.9 \pm 1.3$ & $42.0 \pm 0.8$ & $48 \mathrm{~h}$ \\
Total Lipids (TLs) (g/L) & $21.8 \pm 0.5$ & $22.2 \pm 1.0$ & $24.0 \pm 0.9$ & $25.3 \pm 0.6$ \\
DHA (g/L) & $5.2 \pm 0.3$ & $3.6 \pm 0.1$ & $5.5 \pm 0.4$ & $5.7 \pm 0.1$ \\
DHA/TFA & $24 \pm 0.1$ & $16 \pm 1.1$ & $23 \pm 0.1$ & $22 \pm 0.0$ \\
\hline
\end{tabular}

fluconazole on cell growth and fatty acid biosynthesis during the whole fermentation process, the TFA, DCW and the residual glucose in the culture medium were monitored from 72 to $120 \mathrm{~h}$ after addition of fluconazole at $48 \mathrm{~h}$. From the results obtained, there were no obvious difference in biomass and TFA composition (data not shown). On the other hand, more residual glucose was observed in the fluconazole group than in the control group at $72 \mathrm{~h}$ (Fig. 2a). The observation is attributed to attenuation of glucose absorption from $48 \mathrm{~h}$ to $72 \mathrm{~h}$ due to the addition. Interestingly, TFA production in the fluconazole group began to increase after $72 \mathrm{~h}$ to a maximum of $25 \mathrm{~g} / \mathrm{L}$ at $96 \mathrm{~h}$, which is higher than that of the control group at $96 \mathrm{~h}$. However, the increase maintained only for a short period of time. After the $96 \mathrm{~h}$, the TFA yield started to decrease and reached the same value as the control at $120 \mathrm{~h}$. Combined with the change in the residual glucose, the fluconazole added at the $48 \mathrm{~h}$ influenced the properties of the cell membrane by regulating sterol biosynthesis and the MVA pathway, thus attenuating the absorption of glucose and promoting fatty acid accumulation. To figure out the mechanism, some metabolites of the MVA pathway were observed in the following experiments.

\section{Influences of fluconazole on UM}

Cholesterol, squalene and $\beta$-carotene are the three main kinds of UM in Schizochytrium sp. [11]. Based on the results shown in Fig. 2, the contents of cholesterol, squalene and $\beta$-carotene at 72,96 and $120 \mathrm{~h}$ were measured to investigate the effect of fluconazole addition at $48 \mathrm{~h}$ on UM biosynthesis with an aim of determining UM and fatty acid biosynthesis relationship.

As shown in Fig. 3a, the cholesterol content $(\mathrm{mg} / \mathrm{g}$ lipid) in the fluconazole group was lower than that in the control group at three cultivation times, a demonstration of fluconazole role in inhibiting sterol synthesis. Cholesterol is known to be the main component in the cell membrane and is crucial for the absorption of nutrients. Therefore, a decrease in cholesterol content could account for more residual glucose in the fluconazole group (Fig. 2a). Furthermore, blocking sterol biosynthesis could save more NADPH for fatty acid biosynthesis (Fig. 1), which may cause higher TFA production in the fluconazole group.

The squalene content (mg/g lipid) in the fluconazole group was $45 \%$ higher than that of the control group at $72 \mathrm{~h}$, after which it dropped quickly to near zero at $96 \mathrm{~h}$ and to zero at $120 \mathrm{~h}$ (Fig. 3b). Note that, the point of fluconazole inhibition was found to be between squalene and cholesterol. As shown in Fig. 3a, the inhibition of the sterol pathway by fluconazole resulted in overaccumulation of squalene for a short period of time, a finding that is consistent with Cai-Jun Yue [35]. Note also that, the change in squalene content showed a positive relationship with TFA production. It is known that squalene is an essential natural antioxidant that protects cells from free radicals and reactive oxygen species
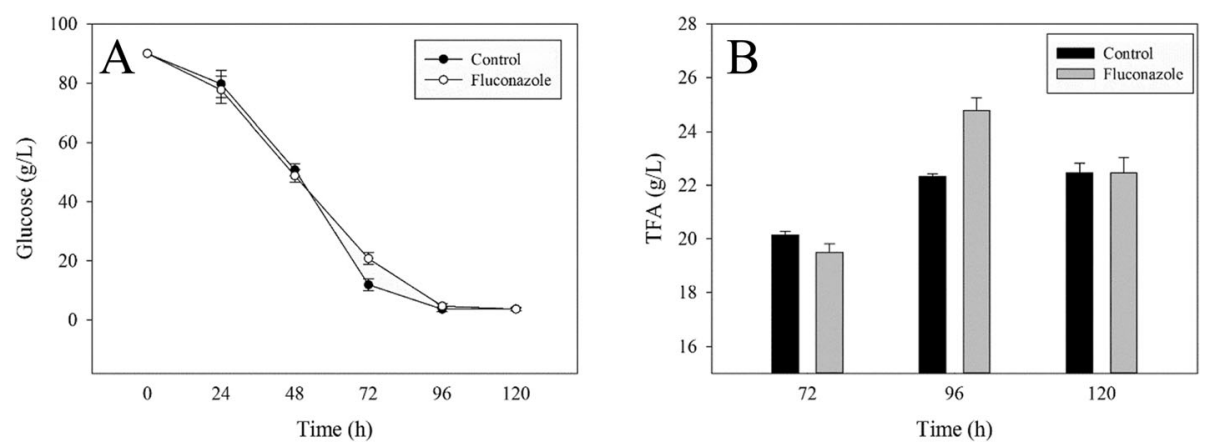

Fig. 2 Residual glucose in the culture medium (a) and effect of adding $60 \mathrm{mg} / \mathrm{L}$ fluconazole at $48 \mathrm{~h}$ on TFA (b) in Schizochytrium. All data are the means of three replicates; vertical bars represent error bars with the value equal to the standard error of the mean 

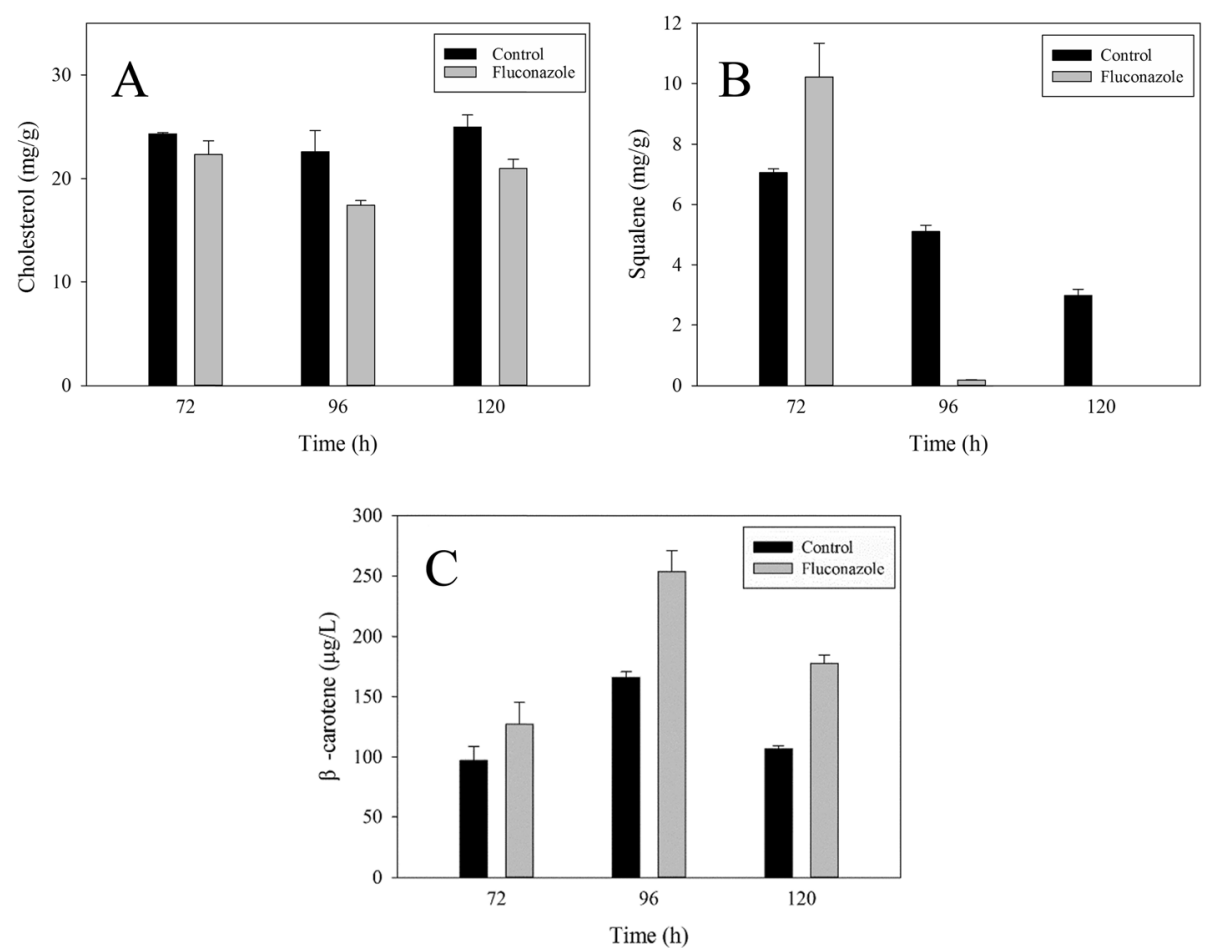

Fig. 3 Effect of fluconazole on cholesterol (a), squalene (b) and $\beta$-carotene (c). All data are the means of three replicates; vertical bars represent error bars with the value equal to the standard error of the mean

(ROS), it also plays a major role in preventing oxidative stresses [36]. Therefore, when more squalene accumulates at $72 \mathrm{~h}$ in the fluconazole group, it may protect fatty acids from being preferentially oxidized from $72 \mathrm{~h}$ to $96 \mathrm{~h}$, leading to consumption of squalene in large quantities and accumulation of fatty acids at $96 \mathrm{~h}$. With the utilization of squalene, TFA production decreased from $96 \mathrm{~h}$ to $120 \mathrm{~h}$ (Fig. $2 \mathrm{~b}$ ).

After the addition of fluconazole in the medium, the $\beta$-carotene production was significantly enhanced than that in the control group (Fig. 3c). In particular, the $\beta$ carotene content in the fluconazole group was $253.5 \mu \mathrm{g} /$ $\mathrm{L}$ at $96 \mathrm{~h}$, which was $53 \%$ higher than that of the control. As shown in Fig. 1, shows $\beta$-carotene biosynthesis shares FPP with the squalene pathway. Therefore, by blocking the sterol pathway by fluconazole, squalene overaccumulates, resulting in more FPPs that are channeled to carotenoid biosynthesis. As a kind of lipid-soluble orange pigment, $\beta$-carotene is another natural antioxidant that could protect intracellular protein, DNA and lipids from oxidation by eliminating ROS [21]. Therefore, more $\beta$-carotene accumulation is favorable for fatty acid accumulation. These results imply that UM affects fatty acid biosynthesis by changing cell membrane function, ROS level and antioxidation. It is also deduced that the metabolic flux of NADPH is regulated by the inhibition of the sterol pathway with fluconazole, which influences fatty acid biosynthesis. To confirm this inference, the intracellular NADPH content was measured in the following experiments.

\section{Influence of fluconazole on G6PDH activity and NADPH content}

$\mathrm{NADPH}$ is an essential reducing agent for anabolism and one of the most important cofactors for the synthesis of fatty acid and UM. Moreover, it is also necessary forantioxidant system [37]. NADPH is mainly synthesized through the pentose phosphate pathway (PPP) and the TCA pathway [6]. On the other hand, glucose-6phosphate dehydrogenase (G6PDH) and malic enzyme (ME) are key enzymes of the two pathways producing $\mathrm{NADPH}$, respectively. Therefore, the addition of $4 \mathrm{~g} / \mathrm{L}$ malic acid at the rapid lipid accumulation stage increased total lipid by $15 \%$ by increasing NADPH supply [38]. In particular, G6PDH plays a role in controlling carbon flux and plays a critical role in providing reducing power in microalgae $[6,39]$. Thus, G6PDH activity and intracellular NADPH content were checked. As shown in Fig. 4a, the G6PDH activities were similar in both groups, which meant that the biosynthesis of $\mathrm{NADPH}$ was not influenced by fluconazole. On the other hand, the intracellular NADPH content showed an interesting change. In the fluconazole group, the $\mathrm{NADPH}$ content was $41 \%$ lower than that of the control 

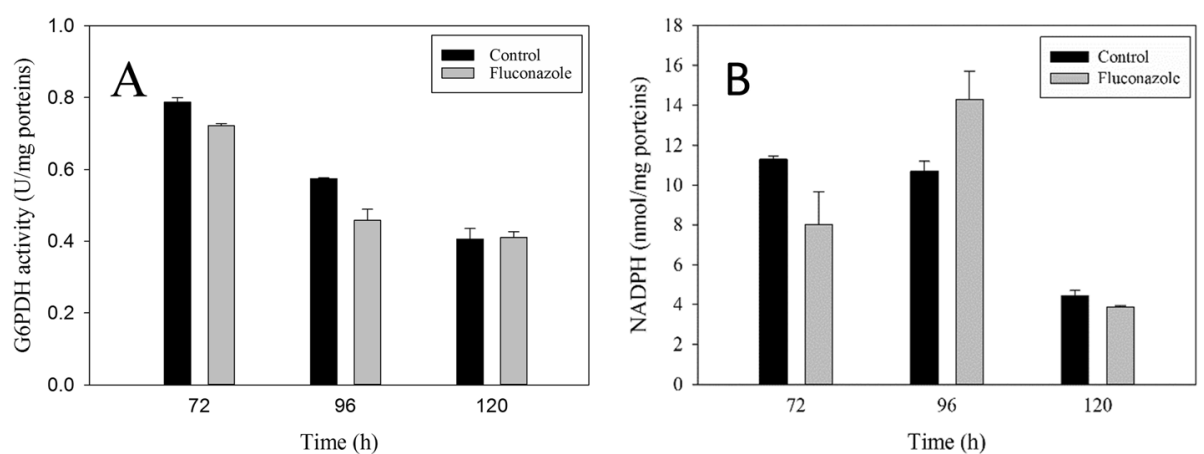

Fig. 4 Effect of fluconazole on G6PDH activity (a) and NADPH content (b). All data are the means of three replicates; vertical bars represent error bars with the value equal to the standard error of the mean

at $72 \mathrm{~h}$, while it increased to $13.7 \mathrm{nmol} / \mathrm{mg}$ protein at 96 $\mathrm{h}$, which was $33 \%$ higher than that of the control (Fig. 4b). In addition, at $120 \mathrm{~h}$, the NADPH content was similar to that of the control group, which meant that the metabolic flux of NADPH was regulated. It is well known that NADPH is consumed in the cholesterol biosynthesis pathway. Therefore, inhibition of cholesterol production by fluconazole inhibits, some NADPH for sterol synthesis is saved and can be shifted to fatty acid biosynthesis. Meanwhile, more squalene was observed at $72 \mathrm{~h}$ in the fluconazole group (Fig. 3b). As well know, squalene can decrease ROS levels by eliminating oxygen free radicals. Sun et al. pointed out that the squalene content of endpoint strains was reduced by $63 \%$ in Schizochytrium sp. under high oxygen supply conditions [40]. Therefore, a higher squalene content may imply lower intracellular ROS levels in the fluconazole group at $72 \mathrm{~h}$, where more NADPH was released from the antioxidant system from $72 \mathrm{~h}$ to $96 \mathrm{~h}$, which could also explain why more NADPH was observed at $96 \mathrm{~h}$ in the fluconazole group [22].

\section{Metabolomics analysis \\ Comparative metabolite profile of with and without fluconazole treatment}

Metabonomics was performed to analyze the intracellular metabolites in the presence of $60 \mathrm{mg} / \mathrm{L}$ fluconazole at 72, 96, and 120 h. As shown in Fig. 5, the PLS-DA pairwise comparisons showed a significant separation of metabolic profiles between the control group and the fluconazole group at 72 (A), 96 (B), and $120 \mathrm{~h}$ (C). A total of 31 kinds of intracellular metabolites were selected and identified with the aid of the NIST database (Table. 3). Furthermore, as shown in Fig. 6, a schematic diagram of the proposed metabolic pathways was mapped out to provide deep insight into the intracellular metabolism of Schizochytrium according to a previous study [33] and the Kyoto Encyclopedia of Genes and Genomes (KEGG).
Fatty acid synthesis variation induced by fluconazole

Fatty acids mainly exist in the forms of triacylglycerol, monoacylglycerol, diacylglycerol, free fatty acids, and phospholipids in Schizochytrium sp. [41]. From the GCMS results (Table 3), only the free fatty acids monostearate and monopalmitin were detected. Other existing forms of fatty acids, such as diacylglycerol and triglyceride, could not be detected in GC-MS given their large size. As shown in Table 3, the concentration of the free fatty acids, including arachidonic acid (ARA) and DHA, was elevated in the fluconazole group. Monostearate and monopalmitin were also elevated at 96 and $120 \mathrm{~h}$. The concentration of free saturated fatty acids, such as palmitic acid and stearic acid, had hardly changed. Therefore, increase in free PUFAs and acylglycerol of saturated fatty acids mainly contributed to the increase in TFA (Fig. 2b). To our knowledge, PUFAs and sterols are important components of the cell membrane. Thus, when sterol biosynthesis is regulated, the biosynthesis and existential forms of PUFA are affected to balance the structural and dynamical properties of the cell membrane.

\section{Metabolic pathways that are related to fatty acid variation induced by fluconazole}

As shown in Table 3 and Fig. 6, the changes in cholesterol and squalene contents are in line with the results in Fig. 3a and Fig. 3b. Moreover, six other kinds of sterols, namely, lanosterol, ergosterol, cholest-7-en-3-ol, cholecalciferol, $\beta$-sitosterol and stigmasterol, were also observed by GC-MS. Due to inhibition of the sterol pathway, cholest-7-en-3-ol, cholesterol and cholecalciferol contents in the fluconazole group were much lower than those in the control group. As the substrate of $14 \alpha-$ demethylase, which was inhibited by fluconazole, the lanosterol content was significantly increased in the fluconazole group, which further resulted in the overaccumulation of squalene. The increased squalene as an antioxidant might scavenge intracellular ROS in 


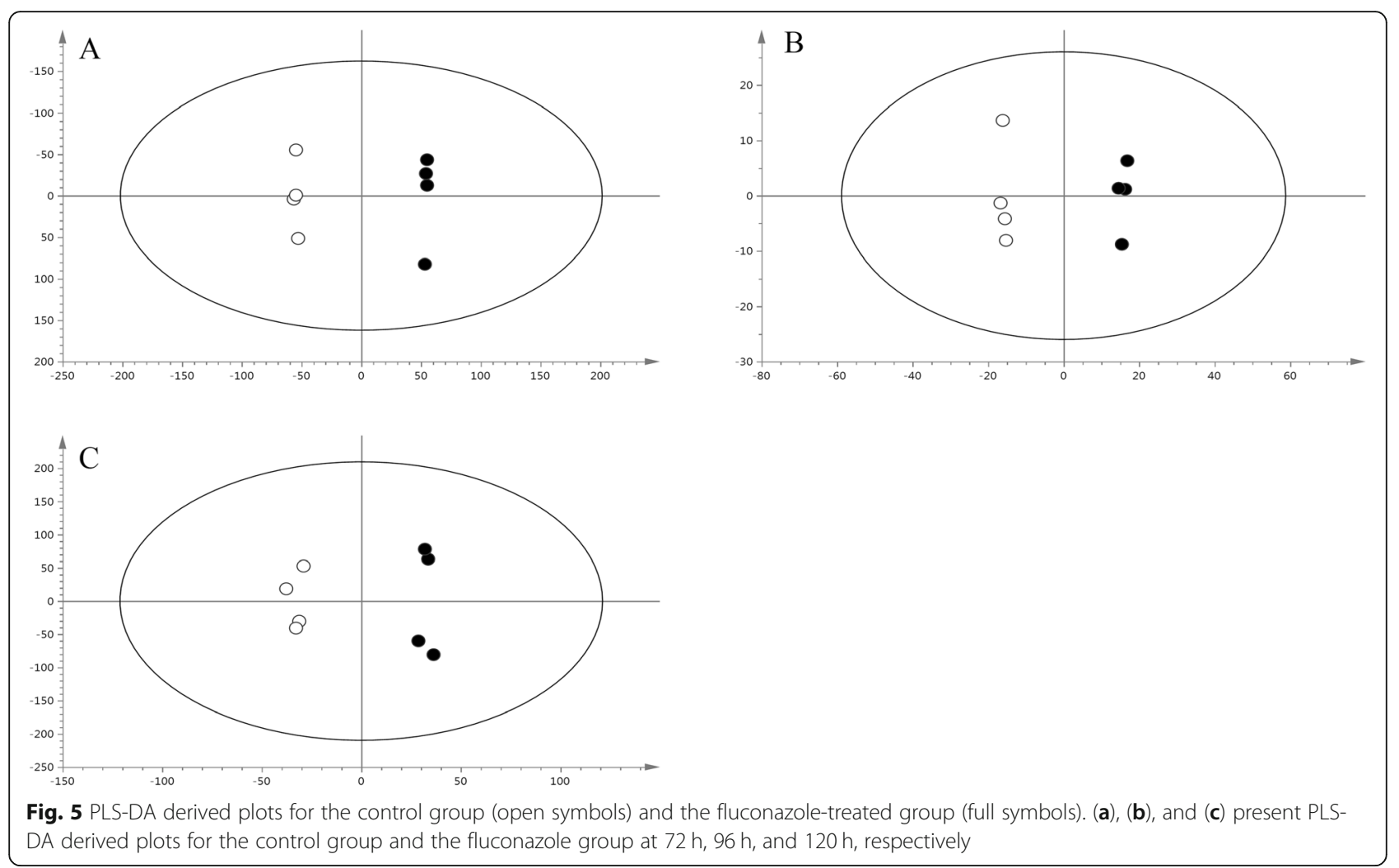

Schizochytrium for lipid accumulation. It is reported that other exogenous additives such as ascorbic acid and sesamol increase the antioxidant capacity of cells for lipid accumulation [42]. On the other hand, it was observed that the content of ergosterol was not significantly affected by fluconazole. Ergosterol is a fungal sterol and is the most important sterol in cell membranes, where it is crucial for cell growth and maintaining morphology. Therefore, the ergosterol may preferentially be synthesized to maintain its activity when the sterol pathway is blocked in marine microalgae. Interestingly, stigmasterol and $\beta$-sitosterol were greatly increased. The observation is attributed to the prompt accumulation of squalene and channeling of more squalene into stigmasterol and $\beta$-sitosterol biosynthesis due to inhibition of lanosterol $14 \alpha$-demethylase activity by fluconazole (Fig. 7) [43]. Stigmasterol and $\beta$ sitosterol are phytosterols, which are the most important components of cell membranes in plants. Compared with cholesterol, stigmasterol has one more double bond, which decreases the fluidity of the cell membrane [18]. This structural aspect could also account for the slow absorption of glucose in fluconazole group. Moreover, stigmasterol has the potential to treat ovarian, prostate, breast and colon cancers [44]; however, its biosynthesis and role have never been reported in marine microalgae. To the best of our knowledge, this is the first report on stigmasterol biosynthesis in marine microalgae. These findings may provide novel insight for future research on Schizochytrium.

The intracellular glucose content decreased in the fluconazole group due to reduction of cell membrane's fluidity as a result of profile change of sterols in the cell membrane, thus retarding the absorption of glucose, as evident by more residual glucose in the culture medium of fluconazole group. An et al. and Saniewski et al. pointed out that sterol and PUFAs play a role in membrane fluidity and permeability, further improving the absorption function of the membrane $[45,46]$. Li et al. also pointed out that MAT overexpression could accelerate glucose absorption by improving membrane fluidity and permeability, and finally enhance carbon flux to the PUFA synthesis [47]. It was also found that the trehalose content of the fluconazole group was less than that of the control group at $72 \mathrm{~h}$ (Table 3 and Fig. 6). The accumulation of trehalose has been associated with the oxidative stress response [48]. Therefore, this result confirmed our previous assumption that lower ROS level was caused by squalene at $72 \mathrm{~h}$.

Acetyl-CoA is a key intermediate metabolite, from which the metabolic flux can enter the MVA pathway, fatty acid biosynthesis and TCA cycle (Fig. 7). 
Table 3 The metabolites content ( $\mu \mathrm{g} / \mathrm{g}$ DCW) responsible for responding to fluconazole in Schizochytrium

\begin{tabular}{|c|c|c|c|c|c|c|}
\hline \multirow[t]{2}{*}{ Metabolites } & \multicolumn{2}{|l|}{$72 \mathrm{~h}$} & \multicolumn{2}{|l|}{$96 \mathrm{~h}$} & \multicolumn{2}{|l|}{$120 \mathrm{~h}$} \\
\hline & control & fluconazole & control & fluconazole & control & fluconazole \\
\hline \multicolumn{7}{|l|}{ TCA cycle } \\
\hline Oxalic acid & $924.4 \pm 22.7$ & $557.3 \pm 18.6^{*}$ & $1317.5 \pm 114.3$ & $597.8 \pm 122.1^{*}$ & $575.9 \pm 48.1$ & $737.7 \pm 33.3^{*}$ \\
\hline Butanedioic acid & $21.4 \pm 7.1$ & $24.1 \pm 11.1$ & $11.3 \pm 1.6$ & $10.9 \pm 2.4$ & $21.1 \pm 6.6$ & $18.1 \pm 5.3$ \\
\hline Citric acid & $22.6 \pm 0.6$ & $8.3 \pm 1.1^{*}$ & $22.6 \pm 9.9$ & $13.6 \pm 6.9^{*}$ & $26.9 \pm 7.8$ & $22.6 \pm 8.3^{*}$ \\
\hline \multicolumn{7}{|l|}{ Glycolysis pathway } \\
\hline Glucose & $8503.2 \pm 591.9$ & $6838.7 \pm 180.3^{*}$ & $654.1 \pm 10.4$ & $904.9 \pm 18.4$ & $154.2 \pm 69.3$ & $118.9 \pm 48.3$ \\
\hline Glycerol & $633.5 \pm 82.5$ & $469.4 \pm 54.5^{*}$ & $351.3 \pm 14.9$ & $226.7 \pm 27.8^{*}$ & $227.5 \pm 17.8$ & $399.7 \pm 1111.9^{*}$ \\
\hline Ethenal & $75.7 \pm 4.9$ & $51.7 \pm 9.8^{*}$ & $33.0 \pm 0.7$ & $25.3 \pm 10.3^{*}$ & $163.3 \pm 29.2$ & $154.7 \pm 31.5$ \\
\hline Phosphate acid & $12,811.2 \pm 324.3$ & $8389.3 \pm 701.5$ & $4413.8 \pm 511.0$ & $4622.4 \pm 119.0^{*}$ & $10,915.5 \pm 2687.4$ & $9960.5 \pm 4480.4$ \\
\hline \multicolumn{7}{|l|}{ Amino acids } \\
\hline Glycine & $74.9 \pm 11.6$ & $74.1 \pm 11.1^{*}$ & $234.5 \pm 23.8$ & $148.5 \pm 9.8^{*}$ & $147.4 \pm 70.0$ & $163.9 \pm 63.2$ \\
\hline L-Serine & $12.2 \pm 3.2$ & $10.1 \pm 5.0$ & $22.1 \pm 1.1$ & $18.6 \pm 1.4^{*}$ & $4.4 \pm 4.4$ & $18.4 \pm 8.2$ \\
\hline$\beta$-Alanine & $0.1 \pm 0.0$ & $0.3 \pm 0.0^{*}$ & $7.4 \pm 0.8$ & $9.0 \pm 1.4^{*}$ & $17.1 \pm 4.4$ & $29.8 \pm 8.6^{*}$ \\
\hline Proline & $225.0 \pm 28.2$ & $202.7 \pm 22.8^{*}$ & $156.1 \pm 55.1$ & $322.9 \pm 75.2^{*}$ & $427.1 \pm 123.8$ & $337.8 \pm 40.7$ \\
\hline L-Glutamic acid & $7.1 \pm 0.4$ & $8.2 \pm 1.9$ & $10.2 \pm 1.6$ & $6.3 \pm 5.0^{*}$ & $9.4 \pm 1.6$ & $8.9 \pm 1.5$ \\
\hline Phenylalanine & $13.7 \pm 0.7$ & $29.0 \pm 5.3^{*}$ & $10.8 \pm 4.6$ & $6.0 \pm 4.5^{*}$ & $21.1 \pm 2.6$ & $14.6 \pm 4.0$ \\
\hline \multicolumn{7}{|c|}{ Pentose phosphate pathway } \\
\hline Xylose & $7.8 \pm 1.0$ & $5.6 \pm 0.5^{*}$ & $10.6 \pm 1.2$ & $7.1 \pm 11.4^{*}$ & $17.8 \pm 3.5$ & $22.5 \pm 3.8$ \\
\hline Ribitol & $30.7 \pm 1.2$ & $20.8 \pm 2.9^{*}$ & $54.1 \pm 0.5$ & $44.7 \pm 23.4^{*}$ & $18.1 \pm 5.3$ & $20.9 \pm 3.0$ \\
\hline Trehalose & $21.1 \pm 7.7$ & $11.9 \pm 11.1^{*}$ & $42.6 \pm 3.7$ & $59.8 \pm 6.1^{*}$ & $45.5 \pm 5.0$ & $69.2 \pm 6.4$ \\
\hline \multicolumn{7}{|l|}{ Fatty acids } \\
\hline Monostearate & $23.5 \pm 16.1$ & $21.5 \pm 10.5^{*}$ & $127.2 \pm 18.5$ & $239.5 \pm 48.2^{*}$ & $155.9 \pm 29.0$ & $242.6 \pm 31.0^{*}$ \\
\hline Monopalmitin & $17.7 \pm 2.3^{*}$ & $17.6 \pm 4.6$ & $57.1 \pm 9.0$ & $83.2 \pm 6.8^{*}$ & $268.0 \pm 47.3$ & $375.8 \pm 60.3^{*}$ \\
\hline Palmitic acid & $1166.0 \pm 77.5$ & $889.9 \pm 119.5$ & $1712.2 \pm 113.8$ & $1262.7 \pm 86.2^{*}$ & $1188.5 \pm 151.0$ & $1224.8 \pm 246.0$ \\
\hline Stearic acid & $1018.4 \pm 107.2$ & $648.4 \pm 157.5^{*}$ & $593.5 \pm 82.7$ & $748.5 \pm 72.6$ & $703.9 \pm 113.1$ & $763.0 \pm 109.9$ \\
\hline Arachidonic acid & $19.9 \pm 4.1$ & $33.8 \pm 4.6^{*}$ & $28.5 \pm 2.5$ & $36.3 \pm 2.4^{*}$ & $41.9 \pm 4.1$ & $61.5 \pm 15.2^{*}$ \\
\hline Doconexent acid & $237.5 \pm 32.4$ & $359.0 \pm 26.9^{*}$ & $314.2 \pm 33.6$ & $267.0 \pm 17.4$ & $169.7 \pm 31.5$ & $271.5 \pm 34.6^{*}$ \\
\hline \multicolumn{7}{|l|}{ Sterols } \\
\hline Squalene & $510.2 \pm 33.8$ & $610.6 \pm 80.0^{*}$ & $161.4 \pm 5.8$ & $63.1 \pm 0.3^{*}$ & $88.6 \pm 10.7$ & $16.8 \pm 8.5^{*}$ \\
\hline Cholesterol & $271.4 \pm 40.9$ & $202.9 \pm 10.2^{*}$ & $246.8 \pm 18.0$ & $95.8 \pm 2.9^{*}$ & $286.8 \pm 28.3$ & $254.2 \pm 20.5$ \\
\hline Cyclo-ergosta & $120.8 \pm 6.3$ & $111.6 \pm 7.9^{*}$ & $194.5 \pm 18.8$ & $204.4 \pm 12.0$ & $198.2 \pm 28.9$ & $287.5 \pm 80.2^{*}$ \\
\hline$\beta$-Sitosterol & $10.9 \pm 2.5$ & $47.8 \pm 3.4^{*}$ & $86.3 \pm 18.8$ & $81.8 \pm 4.7$ & $51.1 \pm 4.8$ & $122.9 \pm 32.4^{*}$ \\
\hline Cholest-7-en-3-ol & $8.2 \pm 0.1$ & $0.6 \pm 0.3^{*}$ & $51.0 \pm 4.5$ & $6.0 \pm 0.4^{*}$ & $48.2 \pm 7.0$ & $8.4 \pm 2.0^{*}$ \\
\hline Cholecalciferol & $7.1 \pm 0.4$ & $2.2 \pm 0.5^{*}$ & $30.5 \pm 4.7$ & $10.4 \pm 0.3^{*}$ & $32.7 \pm 9.7$ & $16.1 \pm 8.2^{*}$ \\
\hline Stigmasterol & $15.0 \pm 6.4$ & $353.7 \pm 29.9^{*}$ & $14.7 \pm 3.7$ & $483.9 \pm 9.9^{*}$ & $19.9 \pm 13.8$ & $638.1 \pm 108.3^{*}$ \\
\hline Lanosterol & $47.0 \pm 4.8$ & $152.9 \pm 2.9^{*}$ & $9.6 \pm 0.7$ & $37.9 \pm 1.0^{*}$ & $9.2 \pm 1.6$ & $72.2 \pm 25.7^{*}$ \\
\hline \multicolumn{7}{|l|}{ Others } \\
\hline Urea & $2103.6 \pm 183.8$ & $1248.0 \pm 130.2^{*}$ & $76.2 \pm 4.2$ & $32.9 \pm 18.6^{*}$ & $71.4 \pm 13.2$ & $59.5 \pm 19.9$ \\
\hline
\end{tabular}

* $p<0.05$

The data represents the contents of metabolites and are showed as the mean \pm SD. All data are four of replicates

Citric acid, oxalic acid, and L-glutamic acid contents were reduced in the fluconazole group at $96 \mathrm{~h}$ (Table 3 and Fig. 6), suggesting that more acetylCoA was channeled into fatty acid biosynthesis from
72 to $96 \mathrm{~h}$, which was consistent with an increase in fatty acid observed at $96 \mathrm{~h}$ in the fluconazole group. Ruch et al. and Cheng et al. showed that acetyl-CoA was used to synthesize malonyl-ACP for fatty acid 


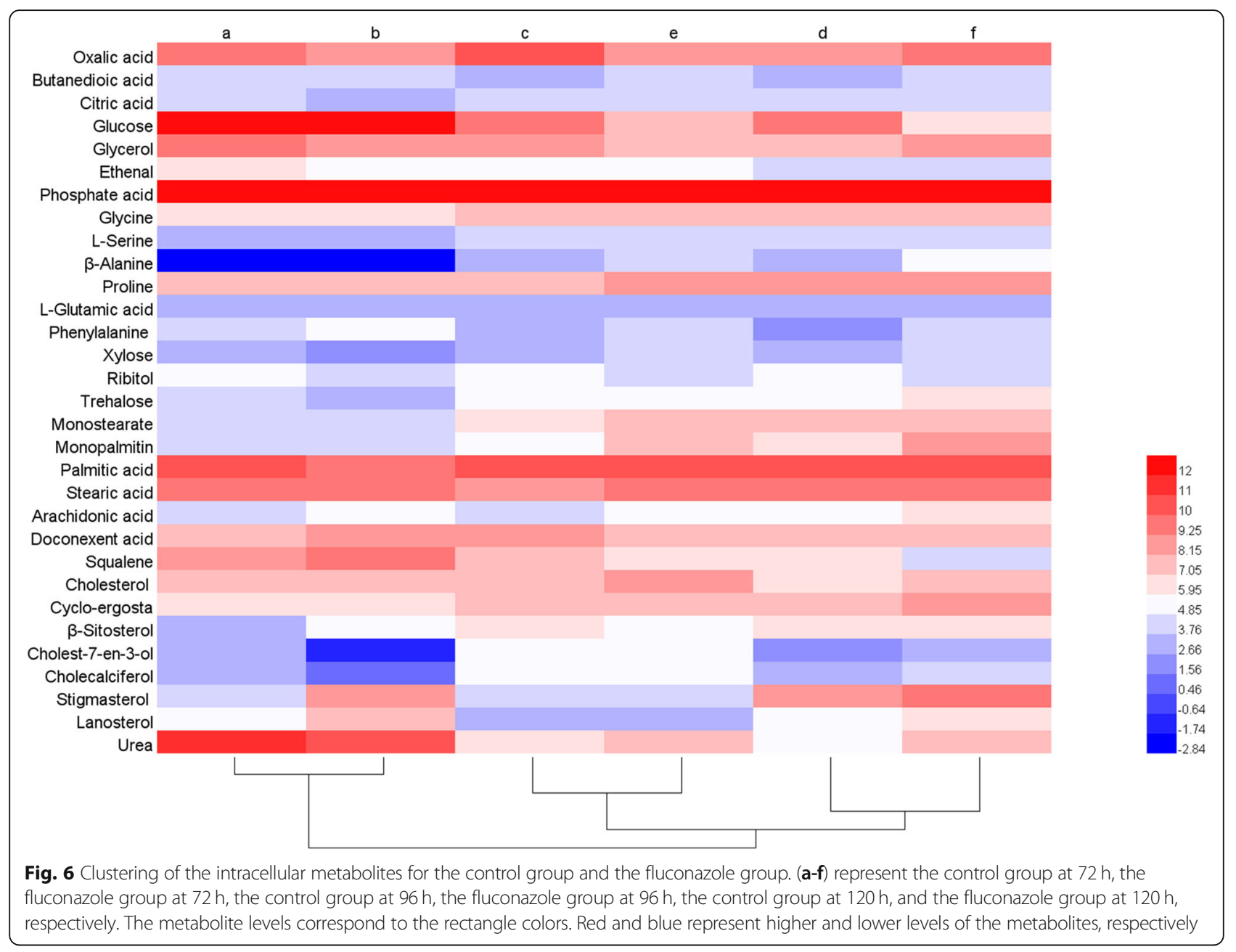

production $[49,50]$. Li et al. pointed out that low citric acid, oxalic acid, and L-glutamic acid content favors fatty acid synthesis by weakening TCA cycle [47]. The decrease in glycine, L-serine and glycerol in the fluconazole group at $72 \mathrm{~h}$ and $96 \mathrm{~h}$ was due to the inhibited utilization of glucose, which reduced the synthesis of glyceraldehyde 3-phosphate. Geng et al. pointed out that some intermediate metabolites including glyceraldehyde-3-phosphate and phosphoenolpyruvic acid in glycolysis pathway reduced, which promoted the glycolytic pathway to synthesize pyruvate [51]. However, the content of phenylalanine in the fluconazole group was much higher than that in the control group at $72 \mathrm{~h}$, but far less at $96 \mathrm{~h}$ and $120 \mathrm{~h}$. This trend was the same as that of squalene and may be because more squalene and IPP accumulated when the sterol pathway was blocked. Both IPP and phenylalanine are substrates of coenzyme Q (CoQ) biosynthesis [14]. It is known that $\mathrm{CoQ}$ is combined with the mitochondrial membrane and is responsible for electron transport by transmitting hydrogen, which is necessary for mitochondrial ATP synthesis. Moreover, CoQ is capable of oxidation resistance by scavenging free radicals. Therefore, the accumulation of IPP induced an increase in phenylalanine production at $72 \mathrm{~h}$ to synthesize more CoQ to improve intracellular oxidation resistance, which might be another reason why more fatty acids accumulated from $72 \mathrm{~h}$ to $96 \mathrm{~h}$.

\section{Conclusion}

The present study investigated the effect of the inhibition of sterol biosynthesis by fluconazole on the UM and fatty acid biosynthesis in Schizochytrium. Blocking the sterol pathway could change the mobility of the cell membrane to postpone the absorption of glucose and shift more NADPH from the MVA pathway to fatty acid biosynthesis. In addition, when the sterol pathway was hindered, squalene over-accumulated and $\beta$-carotene biosynthesis was enhanced, which thus promoted fatty acid accumulation by improving oxidation resistance to protect fatty acids from oxidation. In summary, our work is the first to report the effect of the biosynthesis of UM on fatty acid accumulation 


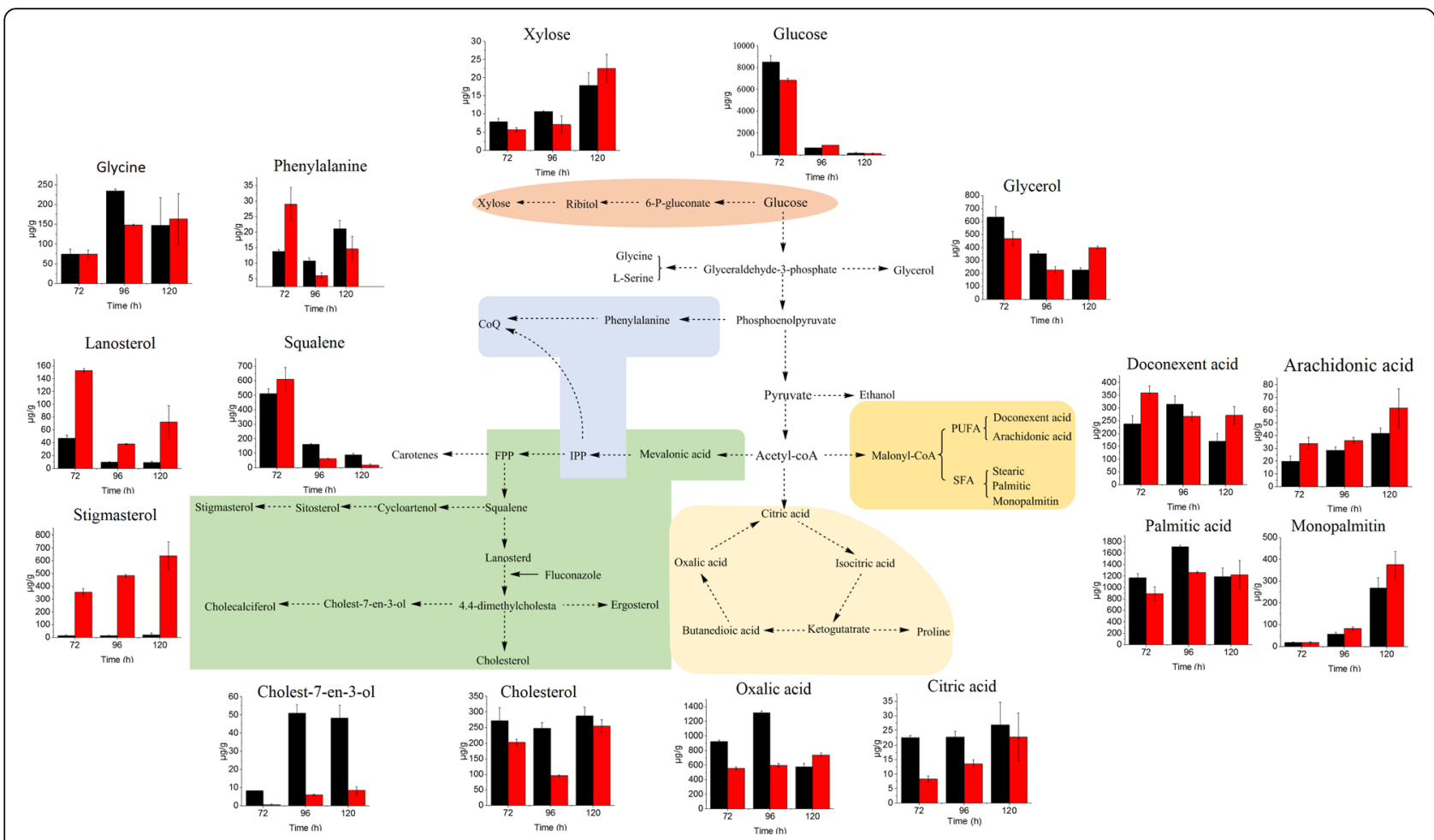

Fig. 7 A schematic diagram of the proposed metabolic pathways in Schizochytrium. The black and red rectangles represent the metabolites in the control group and the fluconazole group, respectively

in Schizochytrium, which provides valuable insights to guide future research in improving the production of PUFA and other valuable molecules, such as $\beta$ carotene, squalene and stigmasterol, in microalgae.

\section{Abbreviations}

DHA: Docosahexaenoic acid; MVA: Mevalonate acid; PUFA: Polyunsaturated fatty acid; TFA: Total fatty acid; TLs: Total lipids; UM: Unsaponifiable matter

\section{Acknowledgements}

The authors are grateful to the Special National Key Research and Development Plan (No. 2016YFD0400205), the Natural Science Foundation of Fujian Province of China (No. 2017 J01077), the Fundamental Research Funds for the Central Universities (No. 20720160077), the National Natural Science Foundation of China (No. 31871779, 21736009, 21676221) and the Xiamen Southern Oceanographic Center (15GYY024NF03). We also gratefully acknowledge Fujian Provincial Scientific and Technological Innovation Platform (2014H2006) for their continuous technical support.

\section{Authors' contributions}

$J \mathrm{~L}, X P L, H Z, X S P$ and ZPL designed the experiments. JL, HZ and TM preformed the experiments. $J \mathrm{~L}, \mathrm{XPL}, \mathrm{HZ}, \mathrm{YHL}, \mathrm{NH}, \mathrm{CYY}$ and $\mathrm{CXC}$ analyzed the results. $J L$ wrote the manuscript which was reviewed and approved by all authors.

\section{Funding}

The Natural Science Foundation of Fujian Province of China, No. 2017 J01077, recipient: Xueping Ling, Ph.D;

The Fundamental Research Funds for the Central Universities, No. 20720160077, recipient: Xueping Ling, Ph.D;

The National Natural Science Foundation of China, No. 21736009, recipient: Yinghua Lu, Ph.D;

The Xiamen Southern Oceanographic Center, No.15GYY024NF03, recipient: Ning He, Ph.D;
The Education and Research Projects for Young and middle-aged Teachers in Fujian, No.JAT170017, recipient: Xueping Ling, Ph.D.

\section{Availability of data and materials}

All data generated or analyzed during this study are included in this manuscript.

Ethics approval and consent to participate Not applicable.

\section{Consent for publication}

Not applicable.

\section{Competing interests}

The authors declare that they have no competing interests.

\section{Author details}

'Department of Chemical and Biochemical Engineering, College of Chemistry and Chemical Engineering, Xiamen University, Xiamen 361005, People's Republic of China. ${ }^{2}$ Fujian Collaborative Innovation Center for Exploitation and Utilization of Marine Biological Resources, Xiamen, Fujian, People's Republic of China. ${ }^{3}$ The Key Lab for Synthetic Biotechnology of Xiamen City, Xiamen University, Xiamen 361005, People's Republic of China.

Received: 28 October 2018 Accepted: 23 October 2019

Published online: 15 November 2019

\section{References}

1. Honda D, Yokochi T, Nakahara T, Erata M, Higashihara T. Schizochytrium limacinum sp. nov., a new thraustochytrid from a mangrove area in the West Pacific Ocean. Mycol Res. 1998;102(4):439-48.

2. Yaguchi T, Tanaka S, Yokochi T, Nakahara T, Higashihara T. Production of high yields of docosahexaenoic acid by Schizochytrium sp. strain SR21. J Am Oil Chem Soc. 1997;74(11):1431-4. 
3. Ji XJ, Ren LJ, Huang $H$. Omega-3 biotechnology: a green and sustainable process for Omega-3 fatty acids production. Front Bioeng Biotechnol. 2015;3:158.

4. Lippmeier JC, Crawford KS, Owen CB, Rivas AA, Metz JG, Apt KE. Characterization of both polyunsaturated fatty acid biosynthetic pathways in Schizochytrium sp. Lipids. 2009;44(7):621-30.

5. Yan J, Cheng R, Lin X, You S, Li K, Rong H, Ma Y. Overexpression of acetyl-CoA synthetase increased the biomass and fatty acid proportion in microalga Schizochytrium. Appl Microbiol Biotechnol. 2013;97(5):1933-9.

6. Cui GZ, Ma Z, Liu YJ, Feng Y, Sun Z, Cheng Y, Song X, Cui Q. Overexpression of glucose-6-phosphate dehydrogenase enhanced the polyunsaturated fatty acid composition of Aurantiochytrium sp. SD116. Algal Res. 2016;19:138-45.

7. Ren LJ, Chen SL, Geng LJ, Ji XJ, Xu X, Song P, Gao S, Huang H. Exploring the function of acyltransferase and domain replacement in order to change the polyunsaturated fatty acid profile of Schizochytrium sp. Algal Res. 2018;29:193-201.

8. Ji XJ, Huang $\mathrm{H}$. Engineering microbes to produce polyunsaturated fatty acids. Trends Biotechnol. 2019;37(4):344-6.

9. Braun R. People's concerns about biotechnology: some problems and some solutions. J Biotechnol. 2002:98(1):3-8.

10. Sun XM, Ren LJ, Zhao QY, Ji XJ, Huang H. Enhancement of lipid accumulation in microalgae by metabolic engineering. Biochim et Biophy Acta BBA Mol Cell Biol Lipids. 2019;1864(4):552-66.

11. Ren LJ, Sun GN, Ji XJ, Hu XC, Huang H. Compositional shift in lipid fractions during lipid accumulation and turnover in Schizochytrium sp. Bioresour Technol. 2014;157:107-13.

12. Goldstein $J$, Brown MS. Regulation of the mevalonate pathway. Nature. 1990;343(6257):425.

13. Ohto C, Muramatsu M, Obata S, Sakuradani E, Shimizu S. Overexpression of the gene encoding HMG-CoA reductase in Saccharomyces cerevisiae for production of prenyl alcohols. Appl Microbiol Biotechnol. 2009;82(5):837-45.

14. Meganathan R. Ubiquinone biosynthesis in microorganisms. FEMS Microbiol Lett. 2001;203(2):131-9.

15. Sun $Y$, Sun L, Shang F, Yan G. Enhanced production of $\beta$-carotene in recombinant Saccharomyces cerevisiae by inverse metabolic engineering with supplementation of unsaturated fatty acids. Process Biochem. 2016; 51(5):568-77.

16. Najle SR, Molina MC, Ruiz-Trillo I, Uttaro AD. Sterol metabolism in the filasterean Capsaspora owczarzaki has features that resemble both fungi and animals. Open Biol. 2016;6(7).

17. Georgopapadakou NH, Dix BA, Smith SA, Freudenberger J, Funke PT. Effect of antifungal agents on lipid biosynthesis and membrane integrity in Candida albicans. Antimicrob Agents Chemother. 1987;31(1):46-51.

18. Bernsdorf C, Winter R. Differential properties of the sterols cholesterol, Ergosterol, a-Sitosterol, trans-7-Dehydrocholesterol, Stigmasterol and Lanosterol on DPPC bilayer order. J Phys Chem B. 2003;107(38):10658-64.

19. Aki T, Hachida K, Yoshinaga M, Katai Y, Yamasaki T, Kawamoto S, Kakizono T, Maoka T, Shigeta S, Suzuki O. Thraustochytrid as a potential source of carotenoids. J Am Oil Chem Soc. 2003;80(8):789.

20. Yue J, Fan KW, Wong TY, Chen F. Fatty acid composition and Squalene content of the marine microalga Schizochytrium mangrovei. J Agric Food Chem. 2004;52(5):1196.

21. Cui Y, Lu Z, Bai L, Shi Z, Zhao WE, Zhao B. $\beta$-Carotene induces apoptosis and up-regulates peroxisome proliferator-activated receptor $\gamma$ expression and reactive oxygen species production in MCF-7 cancer cells. Eur J Cancer. 2007:43(17):2590-601.

22. Shi K, Gao Z, Lin L, Wang WJ, Shi XQ, Yu X, Song P, Ren $\sqcup$, Huang H, Ji XJ. Manipulating the generation of reactive oxygen species through intermittent hypoxic stress for enhanced accumulation of arachidonic acidrich lipids. Chem Eng Sci. 2018;186:36-43.

23. Rice C, Cooke M, Treloar N, Vollbrecht P, Stukey J, McDonough V. A role for MGA2, but not SPT23, in activation of transcription of ERG1 in Saccharomyces cerevisiae. Biochem Biophys Res Commun. 2010; 403(3-4):293-7

24. Burden RS, Cooke DT, Carter GA. Inhibitors of sterol biosynthesis and growth in plants and fungi. Cheminform. 1989;28(7):1791-804.

25. Miao L, Chi S, Tang Y, Su Z, Yin T, Guan G, Li Y. Astaxanthin biosynthesis is enhanced by high carotenogenic gene expression and decrease of fatty acids and ergosterol in a Phaffia rhodozyma mutant strain. FEMS Yeast Res. 2011;11(2):192-201.
26. Ling XP, Guo J, Liu XT, Zhang X, Wang N, Lu Y, Ng IS. Impact of carbon and nitrogen feeding strategy on high production of biomass and docosahexaenoic acid (DHA) by Schizochytrium sp. LU310. Bioresour Technol. 2015;184:139-47.

27. Miller GL. Use of Dinitrosalicylic acid reagent for determination of reducing sugar. Anal Biochem. 1959:31(3):426-8.

28. Dhara R, Bhattacharyya DK, Ghosh M. Analysis of sterol and other components present in unsaponifiable matters of mahua, Sal and mango kernel oil. J Oleo Sci. 2010;59(4):169-76.

29. Sun G, Ren L, Liang QU, Juan LI, Yuanwei HU, Huang H. Component characteristics of single cell lipid produced by Schizochytrium sp. China Oils \& Fats. 2013;38(6):70-3.

30. Xie Y, Ho SH, Chen CN, Chen CY, Ng IS, Jing KJ, Chang JS, Lu Y. Phototrophic cultivation of a thermo-tolerant Desmodesmus sp. for lutein production: effects of nitrate concentration, light intensity and fed-batch operation. Bioresour Technol. 2013;144:435-44.

31. Liu B, Liu J, Sun P, Ma X, Jiang Y, Chen F. Sesamol enhances cell growth and the biosynthesis and accumulation of Docosahexaenoic acid in the microalga Crypthecodinium cohnii. J Agric Food Chem. 2015;63(23):5640-5.

32. Bradford MM. A rapid and sensitive method for the quantitation of microgram quantities of protein utilizing the principle of protein-dye binding. Anal Biochem. 1976;72(s 1-2):248-54.

33. Yu XJ, Sun J, Sun YQ, Zheng JY, Wang Z. Metabolomics analysis of phytohormone gibberellin improving lipid and DHA accumulation in Aurantiochytrium sp. Biochem Eng J. 2016;112:258-68.

34. Yu XJ, Sun J, Zheng JY, Sun YQ, Wang Z. Metabolomics analysis reveals 6benzylaminopurine as a stimulator for improving lipid and DHA accumulation of Aurantiochytrium sp. J Chem Technol Biotechnol. 2016; 91(4):1199-207.

35. Yue CJ, Jiang Y. Impact of methyl jasmonate on squalene biosynthesis in microalga Schizochytrium mangrovei. Process Biochem. 2009;44(8): 923-7.

36. Kohno Y, Egawa Y, Itoh S, Nagaoka SI, Takahashi M, Mukai K. Kinetic study of quenching reaction of singlet oxygen and scavenging reaction of free radical by squalene in n-butanol. Biochim Biophys Acta. 1995;1256(1):52-6.

37. Carreras A. The dehydrogenase-mediated recycling of NADPH is a key antioxidant system against salt-induced oxidative stress in olive plants. Plant Cell Environ. 2006;29(7):1449.

38. Ren $L$, Huang $H$, Xiao AH, Lian M, Jin LJ, Ji XJ. Enhanced docosahexaenoic acid production by reinforcing acetyl-CoA and NADPH supply in Schizochytrium sp. HX-308. Bioprocess Biosyst Eng. 2009;32(6):837.

39. Xue J, Balamurugan S, Li DW, Liu YH, Zeng H, Wang L, Yang WD, Liu JS, Li HY. Glucose-6-phosphate dehydrogenase as a target for highly efficient fatty acid biosynthesis in microalgae by enhancing NADPH supply. Metab Eng. 2017:41:212-21.

40. Sun XM, Ren LJ, Ji XJ, Chen SL, Guo DS, Huang H. Adaptive evolution of Schizochytrium sp. by continuous high oxygen stimulations to enhance docosahexaenoic acid synthesis. Bioresour Technol. 2016;211:374-81.

41. Fan KW, Jiang Y, Faan YW, Chen F. Lipid characterization of mangrove thraustochytrid--Schizochytrium mangrovei. J Agric Food Chem. 2007;55(8):2906-10.

42. Sun XM, Ren LJ, Zhao QY, Ji XJ, Huang H. Microalgae for the production of lipid and carotenoids: a review with focus on stress regulation and adaptation. Biotechnol Biofuels. 2018;11(1):272

43. Raksha BR, Siva R, Vino S, Babu S. Spatio-varietal differences in stigmasterol biosynthesis in tomato and overexpression of a sterol desaturase gene for enhanced stigmasterol production. In Vitro Cell Dev Biol Plant. 2016;52(6):571-9.

44. Gabay O, Sanchez C, Salvat C, Chevy F, Breton M, Nourissat G, Wolf C, Jacques C, Berenbaum F. Stigmasterol: a phytosterol with potential antiosteoarthritic properties. Osteoarthr Cartil. 2010;18(1):106-16.

45. Saniewski M, Czapski J. M H: fatty acid and sterol contents during tulip leaf senescence induced by methyl jasmonate. Acta Agrobot. 2013:47(2):89-95.

46. An D, Gordon Jl. Membrane sphingolipids as essential molecular signals for Bacteroides survival in the intestine. Proc Natl Acad Sci U S A. 2011 108(11):4666-71.

47. Li Z, Tong M, Ling XP, Li J, He N. Overexpression of Malonyl-CoA: ACP Transacylase in Schizochytrium sp. to improve polyunsaturated fatty acid production. J Agric Food Chem. 2018;66(21):5382-91.

48. Martinez-Moya P, Niehaus K, Alcaino J, Baeza M, Cifuentes V. Proteomic and metabolomic analysis of the carotenogenic yeast Xanthophyllomyces dendrorhous using different carbon sources. BMC Genomics. 2015;16:289. 
49. Ruch FE, Vagelos PR. The isolation and general properties of Escherichia coli malonyl coenzyme A-acyl carrier protein transacylase. J Biol Chem. 1973;248(23):8086

50. Cheng RB, Yang YQ, Zhong B, Lin XM, Zhi X. Cloning and functional analysis of putative malonyl-CoA:acyl-carrier protein transacylase gene from the docosahexaenoic acid-producer Schizochytrium sp. TIO1101. World J Microbiol Biotechnol. 2013;29(6):959-67.

51. Geng $\sqcup$, Chen SL, Sun XM, Hu XC, Ji XJ, Huang H, Ren L. Fermentation performance and metabolomic analysis of an engineered high-yield PUFAproducing strain of Schizochytrium sp. Bioprocess Biosyst Eng. 2019;42(1):71-81.

\section{Publisher's Note}

Springer Nature remains neutral with regard to jurisdictional claims in published maps and institutional affiliations.

Ready to submit your research? Choose BMC and benefit from:

- fast, convenient online submission

- thorough peer review by experienced researchers in your field

- rapid publication on acceptance

- support for research data, including large and complex data types

- gold Open Access which fosters wider collaboration and increased citations

- maximum visibility for your research: over $100 \mathrm{M}$ website views per year

At BMC, research is always in progress.

Learn more biomedcentral.com/submissions 